\title{
APLIKASI FUZZY PADA PERMASALAHAN PROGRAM TAK-LINIER
}

(Application of Fuzzy in the Non Linear Programing Problem)

\author{
ABRAHAM ZACARIA WATTIMENA \\ Staf Jurusan Matematika Fakultas MIPA Universitas Pattimura \\ Jl. Ir. M. Putuhena, Kampus Unpatti, Poka-Ambon \\ email: ampiwattimena@rocketmail.com
}

\begin{abstract}
One of the most purpose of non linear programing is to determine the optimal solution of its objective function. If the objective function of a certain non linear programing only possess a uniqe value function, it is easy to calculate its optimal solution. However, if the objective function of non linier programing possess multi functions, so there are two possibilities to determine their optimal solutions. Theses depend on whether there are conflic among them or not. In order to make them more easier, the fuzzy parameter could be applied to calculate the optimal solution.
\end{abstract}

Keywords: Non linear progaming, optimal solution, objective function, fuzzy parameter.

\section{PENDAHULUAN}

Salah satu tujuan dalam permasalahan program taklinier (NLP) adalah menentukan solusi optimal. Jika fungsi tujuan (objective) dari NLP merupakan fungsi bernilai tunggal maka solusi optimal dapat ditentukan. Tetapi jika fungsi tujuannya merupakan multi-objektif (multiobjective) sehingga NLP menjadi permasalahan progrm tak-linier multi-objektif (MONLP), maka ada dua kasus dalam menentukan solusi dari MONLP tersebut. Kasus pertama, jika pada fungsi-fungsi tujuan tersebut tidak terjadi konflik maka solusi MONLP disebut solusi optimal. Kasus kedua, jika pada fungsi-fungsi tujuan terjadi konflik maka solusinya disebut solusi optimal pareto.

Di samping itu juga, dalam masalah program taklinier banyak dijumpai adanya parameter-parameter yang bersifat fuzzy, misalnya kapasitas yang tersedia kira-kira $m$ satuan. Proses pengambilan keputusan untuk menentukan suatu nilai ini tentunya memerlukan suatu teori. Untuk itu peranan teori fuzzy sangat perlu dikembangkan. Evolusi penting tentang kekaburan atau ketidak-pastian dari suatu konsep yang modern telah diperkenalkan oleh Lofti A. Zadeh pada tahun 1965 ( Klir and Yuan, 1995), yang mengemukakan tentang teori himpunan fuzzy, dimana anggota-anggotanya tidak hanya berdasarkan pada masalah ketegasan atau penguatan, tetapi juga pada masalah kederajatan.

\section{TINJAUAN PUSTAKA}

Pemakaian bilangan fuzzy yang digunakan dalam konteks pengambilan keputusan, khususnya dalam masalah program linear tidak konveks (nonconvex) telah dikemukan oleh Sakawa dan Yauchi (1995). Begitu juga dengan Ali (2001) mengemukakan tentang pendekatan persamaan diferensial untuk menyelesaikan masalah optimal dengan vector fuzzy, dimana vector fuzzy diasumsikan mempunyai karakteristik yang sama dengan bilangan fuzzy. Dari pembahasan tersebut menunjukkan bahwa bilangan fuzzy dapat digunakan untuk menyelesaikan berbagai permasalahan tetapi masih bersifat umum.

Berdasarkan uraian di atas, maka dalam penelitian ini akan dibahas secara khusus, yaitu tentang aplikasi bilangan fuzzy yang digunakan untuk menyelesaikan permasalahan program tak-linier multi-objektif dengan parameter fuzzy (MONLP-FP).

\section{HASIL DAN PEMBAHASAN}

Bentuk umum permasalahan (MONLP-FP) dinyatakan dengan:

$$
\begin{gathered}
\min f(x, \bar{a})=f_{1}\left(x, \overline{a_{1}}\right), \ldots, f_{k}\left(x, \overline{a_{k}}\right) \\
\text { s.t. } x \in X(\bar{b})=\left\{x \in R^{n} / g_{j}\left(x, \overline{a_{k}}\right) \leq 0, j=\right. \\
1, \ldots, m\}
\end{gathered}
$$


dimana $\bar{a}=\left(\overline{a_{1}}, \ldots, \overline{a_{k}}\right)$ adalah parameter fuzzy . $\bar{b}=\left(\overline{b_{1}}, \ldots, \overline{b_{m}}\right)$ adalah parameter fuzzy pada fungsi Kendal $g j\left(x, \overline{b_{J}}\right) ; j=1, \ldots, m$. Parameter-parameter fuzzy di sini diasumsikan sebagai bilangan fuzzy, sebagaimana yang dikemukakan oleh Dubois dan Prade (1978), yaitu bilangan fuzzy $\bar{p}$ dengan fungsi keanggotannya $\mu_{\bar{p}}(p)$ merupakan pemetaan kontinu dari - ke interval tertutup $[0,1], \mu_{\bar{p}}(p)=0$ untuk semua $p \in(-\infty, p 1], \mu_{\bar{p}}(p)$ tidak turun sempurna dan kontinu pada $[p 1, p 2], \mu_{\bar{p}}(p)=1$ untuk semua $p \in$ $[p 2, p 3], \mu \bar{p}(p)$ tidak naik sempurna dan kontinu pada $[p 3, p 4]$ dan $\mu \bar{p}(p)=0$ untuk semua $p \in[p 4, \infty)$ (Sakawa, 1993).

\section{Definisi 1.}

Misalkan $A$ adalah himpunan fuzzy. $A$ dikatakan bilangan fuzzy jika $A$ adalah himpunan fuzzy normal. $A$ adalah himpunan fuzzy konveks, A mempunyai support terbatas dan semua $\alpha$ level dari $A$ adalah interval tertutup (Wang, 1997).

Bilangan fuzzy triangular $A$ dinyatakan dengan $A=(a, b, c)$ adalah himpunan fuzzy $A$ yang fungsi keanggotaannya adalah

$\mu_{A}(x)=\left\{\begin{array}{c}f_{A}(x), a \leq x<b \\ 1, b \leq x \leq c \\ g_{A}(x), c<x \leq d \\ 0, \text { untuk yang lainnya }\end{array}\right.$

dimana $a, b, c, d \in A$ dengan $a<b<c<d, f_{A}$ adalah fungsi bernilai riil yang monoton naik dan kontinu kanan, dan $g_{A}$ adalah fungsi bernilai real yang monoton turun dan kontinu kiri.

Himpunan $\alpha$-level dari interval fuzzy $A$ untuk semua $\alpha \in(0,1]$ dinyatakan dengan

$$
A_{\alpha}=\left\{\begin{array}{lr}
{\left[f_{A}^{-1}(\alpha), g_{A}^{-1}(\alpha)\right]} & , \alpha \in(0 \in, 1) \\
{[b, c]} & \alpha=1
\end{array}\right.
$$

dimana $f_{A}^{-1}$ dan $g_{A}^{-1}$ adalah fungsi invers dari $f_{A}$ dan $g_{A}$ (Klir, 1997).

Berdasarkan persamaman (5), maka himpunan a - level dari bilangan fuzzy triangular adalah

$$
A_{\alpha}=[(b-a) \alpha+a, c-(c-b) \alpha]
$$

Untuk menentukan solusi op timal dari masalah pada persamaan (1) maka parameter-parameter fuzzy diasumsikan sebagai bilangan fuzzy triangular yaitu bilangan fuzzy $\bar{p}$ dengan fungsi keanggotannya $\mu_{\bar{p}}(p)$ dinyatakan dengan

$$
\mu_{\overline{p_{l}}}\left(p_{i}\right)= \begin{cases}0 & ,-\infty<p_{i}<p_{i}^{1} \\ \frac{p_{i}-p_{i}^{1}}{p_{i}^{2}-p_{i}^{1}} & , p_{i}^{1} \leq p_{i} \leq p_{i}^{2} \\ \frac{p_{i}^{3}-p_{i}}{p_{i}^{3}-p_{i}^{2}} & , p_{i}^{2} \leq p_{i} \leq p_{i}^{3} \\ 0 & , p_{i}^{3} \leq p_{i}<+\infty\end{cases}
$$

dimana $\bar{p}_{\imath}$ menyatakan parameter fuzzy $\bar{a}_{i}, i=$ $1, \ldots, k$; dan $\overline{b_{\jmath}}, j=1, \ldots, m ; p_{i}^{t}$ diasumsikan sebagai bilangan fuzzy

$a_{i}^{t}, i=1, \ldots, k$; dan $b_{j}^{t}, j=1, \ldots, m$; dengan $t=1,2,3$.

\section{Definisi 2.}

Himpunan $\alpha$-level dari bilangan fuzzy $\bar{a}_{i}(i=$ $1, \ldots, k)$ dan $\bar{b}_{i}(j=1, \ldots, m)$ didefinisikan sebagai himpunan bias $L_{\alpha}(\bar{a}, \bar{b})$ dengan degree dari fungsi keanggotaan lebih besar atu sama dengan level $\alpha$, yaitu (Sakawa, 1993 dan Ammar, 1997)

$$
\begin{gathered}
L_{\alpha}(\bar{a}, \bar{b})=\left\{(a, b) \mid \mu_{\bar{a}_{i}}\left(a_{i}\right) \geq \alpha(i=1, \ldots, k), \mu_{\bar{b}_{j}}\left(b_{j}\right) \geq\right. \\
\alpha(j=1, \ldots, m)\}
\end{gathered}
$$

Himpunan a-level dari bilangan fuzzy $\bar{a}_{i}$ dan $\bar{b}_{j}$ dapat juga ditentukan berdasarkan persamaan (5) sehingga himpunan $a$-level persamaan (7) adalah

$$
p_{i(\alpha)}=\left[z_{1}, z_{2}\right]
$$

Dengan $z_{1}=\left(\mathrm{p}_{\mathrm{i}}^{2}-\mathrm{p}_{\mathrm{i}}^{1}\right) \alpha+p_{i}^{1}$ dan $z_{2}=p_{i}^{3}\left(\mathrm{p}_{\mathrm{i}}^{2}-\mathrm{p}_{\mathrm{i}}^{2}\right) \alpha$. Selanjutnya dengan menggunakan persamaan (9) maka persamaan (1) dapat diformulasikan ke bentuk a -MONLP, yaitu

$$
\left.\begin{array}{c}
\min f(x, a)=\left(f_{1}\left(x, a_{1}\right), f_{2}\left(x, a_{2}\right), \ldots, f_{k}\left(x, a_{k}\right)\right) \\
\text { s.t. } x \in X(b)=\left\{\left\{x \in R^{n} \mid\right.\right. \\
\left.g_{j}\left(x, b_{j}\right) \leq 0, j=1, \ldots m\right\} \\
(a, b) \in L_{\alpha}(\bar{a}, \bar{b})
\end{array}\right\}
$$

Solusi optimal persamaan (10) untuk degree $\alpha$ tertentu, dinamakan solusi optimal $\alpha$ - pareto yang didefinisikan sebagai berikut.

\section{Definisi 3.}

$\bar{x} \in X(b)$ dikatakan solusi optimal $\alpha$-pareto pada permasalahan $\alpha$-MONLP jika dan hanya jika tidak ada selain $x \in X(b),(a, b) \in L_{\alpha}(\bar{a}, \bar{b})$ sedemikian sehingga $f_{i}\left(\bar{x}, \bar{a}_{i}\right)$ dan memenuhi ketaksamaan tegas sedikitnya untuk satu $i$, dimana nilai dari parameter $(\bar{a}, \bar{b})$ dikatakan parameter optimal $a$ - level (Sakawa, 1993 dan Ammar, 1997).

Solusi optimal $\alpha$-pareto persamaan (10) ditentukan menggunakan pendekatan metode bobot yang dinyatakan dengan

$$
\left.\begin{array}{l}
\min \sum_{i=1}^{k} w_{i} f_{i}\left(x, a_{i}\right) \\
\text { s.t. } x \in X(b),(a, b) \in L_{\alpha}(\bar{a}, \bar{b})
\end{array}\right\}
$$

Dimana $w_{i} \leq 0, i=1, \ldots, k$; adalah himpunan bobot dengan

$$
\sum_{i=1}^{k} w_{i}=1
$$


Himpunan bobot dinyatakan dengan

$$
w_{i}=\frac{f_{i}^{\max }-f_{i}^{\min }}{\sum_{i=1}^{k}\left(f_{i}^{\text {max }}-f_{i}^{\text {min }}\right)}
$$

Persamaan (12) dihitung berdasarkan solusi compromise, yaitu menentukan nilai minimum dan nilai maksimum dari setiap fungsi tujuan, dengan $\alpha=0$ untuk nilai minimum dan $\alpha=1$ untuk nilai maksimum, yang dinyatakan dengan

$$
\left.\begin{array}{c}
\min f_{1}\left(x, a_{i}\right) \\
\text { s.t. } x \in X(b) \\
\mu_{\bar{a}_{i}}\left(x, a_{i}\right)=0, \mu_{\bar{b}_{j}}\left(x, b_{j}\right)=0
\end{array}\right\}
$$

Dan

$$
\left.\begin{array}{c}
\min f_{1}\left(x, a_{i}\right) \\
\text { s.t. } x \in X(b) \\
\mu_{\bar{a}_{i}}\left(x, a_{i}\right)=1, \mu_{\bar{b}_{j}}\left(x, b_{j}\right)=1
\end{array}\right\}
$$

Permasalahan di bawah ini merupakan suatu contoh nyata yang berbentuk MONLP-FP, yang hasil perhitungannya diperoleh dengan implementasi program Matlab 5.3.0.

Misalkan sebuah perusahaan membangun dua pabrik, yaitu pabrik A dan pabrik B. Keuntungan total diperkirakan $a_{1}$ (kira-kira 3) kali dari hasil kali dua pabrik $\left(a_{1} x_{1} x_{2}\right)$ dalam ratusan dolar per ton, dimana $x_{1}$ adalah produksi dari pabrik A dan $x_{2}$ adalah produksi dari pabrik $\mathrm{B}$ ( $x_{1}$ dan $x_{2}$ dalam ton per hari). Adapun biaya proses inventory dari pabrik $\mathrm{A}$ adalah $\left(x_{1}-a_{2}\right)^{2}$, dimana $a_{2}$ adalah "kira-kira 4" dan dari pabrik B sebesar $\left(x_{2}\right)^{2}$ dalam ratusan dolar per ton. Asumsikan bahwa produksi yang dikombinasikan dari pabrik $A$ dan pabrik $B$ diperkirakan tidak melebihi $b_{1}$ (kira-kira 5) ton per hari.

Tujuan perusahaan adalah untuk memaksimumkan keuntungan total dan juga meminimumkan biaya proses inventory.

Persoalan tersebut dapat difor mulasikan menjadi

$$
\left.\begin{array}{c}
\min \left[-\bar{a}_{1} x_{1} x_{2},\left(x_{1}-\bar{a}_{2}\right)^{2}+x_{2}^{2}\right] \\
\text { s.t. } x_{1}+x_{2}-\bar{b}_{1} \leq 0, \\
x_{1} \geq 0, x_{2} \geq 0
\end{array}\right\}
$$

dengan fungsi keanggotaan sebagaimana persamaan (7), dimana $\bar{p}_{i}$ menyatakan parameter fuzzy $\bar{a}_{i}, i=$ 1,2 dan $\bar{b}_{1}$.

Parameter fuzzy pada permasalahan di atas dapat dinyatakan sebagaimana persamaan (3) sehingga diperoleh :

$a_{1}=$ "kira - kira3"atau $a_{1}^{t}=(1,2,3)$ dimana $m=$ $b=3$ dan $m_{1}=2 ; a_{2}=$ "kira-kira 4" atau $a_{1}^{t}=$ $(2,4,6)$ dimana $m=b=4$ dan $m_{1}=2 ; b_{1}=$ "kira-kira 5 " atau $b_{1}^{t}=(3,5,7)$ dimana $m=b=$ 5 dan $m_{1}=2$.

Berdasarkan persamaan (9) untuk $\alpha=0.64$ maka diperoleh $a_{1(0.64)}=[4.3,5.7]$. sehingga persamaan (15) dapat diformulasikan menjadi bentuk $\alpha-$ MNOLP, yaitu:

$$
\left.\begin{array}{c}
\min w_{1}\left[-a_{1} x_{1} x_{2},\left(x_{1}-a_{2}\right)^{2}+x_{2}^{2}\right] \\
\text { s.t. } x_{1}+x_{2}-b_{1} \leq 0, x_{1} \geq 0, x_{2} \geq 0, \\
a_{1} \in[2.3,3.7], a_{2} \in[3.3,4.7], b_{1} \in[4.3,5.7]
\end{array}\right\}
$$

Selanjutnya persamaan (11) dapat ditulis menjadi:

$$
\left.\begin{array}{c}
w_{2}\left(\left(x_{1}-a_{2}\right)^{2}+x_{2}^{2}\right) \\
\text { s.t. } x_{1}+x_{2}-b_{1} \leq 0 \\
2.3 \leq a_{1} \leq 3.7 \\
3.3 \leq a_{2} \leq 4.7 \\
4.3 \leq b_{1} \leq 5.7 \\
x_{1} \geq 0, x_{2} \geq 0
\end{array}\right\}
$$

Nilai minimum bilangan fuzzy berlaku untuk $\alpha=0$, sehingga diperoleh $\min (1,3,5)=1, \min (2,4,6)=$ 2 dan $\min (3,5,7)=3$. Sedangkan nilai maksimum bilangan fuzzy berlaku untuk $\alpha=1$, sehingga diperoleh maks $(3,5,7)=5$.

Berdasarkan nilai maksimum dan nilai minimum bilangan fuzzy tersebut, maka dengan menggunakan persamaan (13) diperoleh $f_{1}^{\text {min }}=-2.25$ dan $f_{2}^{\text {min }}=0$, sedangkan menggunakan persamaan (14) diperoleh $f_{1}^{\max }=0$, dan $f_{2}^{\max }=14$. Dengan mensubstitusikan nilai-nilai ini pada persamaan (12) maka diperoroleh $w_{1}=0.052$ dan $w_{2}=0.948$. selanjutnya nilai $w_{1}$ dan $w_{2}$ disubstitusikan kepersamaan (17). Akhirnya dengan menyelesaikan persamaan (17) diperoleh $\left(x_{1}, x_{2}, a_{1}, a_{2}, b_{1}\right)=(4.8,0.5,3.2,4.7,5.3)$ yang yang merupakan solusi optimal pareto, dengan nilai minimum $f=-0.15799$ dimana $f_{1}=-7.7784$ dan $f_{2}=0.26$.

Hasil ini menunjukan bahwa untuk $\alpha=0.64$ akan diperoleh hasil produksi dari pabrik A sebesar 480 ton per hari dan hasil produksi dari pabrik B sebesar 50 ton per hari. Keuntungan total sebesar 777.84 Dolar per ton dan biaya proses inventiri sebesar 26 dolar per ton.

\section{KESIMPULAN}

Berdasarkan pembahasan di atas maka dapat disimpulkan :

1. Masalah program tak-linier multi-objetif dengan parameter fuzzy dapat diformulasikan menjadi masalah program tak-linier multi-objektif tidak-fuzzy dengan menggunakan himpunan $\alpha$-level dari bilangan fuzzy triangular;

2. Solusi optimal pada permasalahan program tak-linier multi-objektif dengan parameter fuzzy untuk degree $\alpha$ tertentu, $\alpha \in(0,1)$ diperoleh dengan menyelesaikan permasalahan program tak-linier multi-objektif tidakfuzzy menggunakan pendekatan metode bobot.

3. Solusi optimal yang diharapkan bergantung pada pemilihan nilai $\alpha \in(0,1)$, jika nilai $\alpha$ semakin kecil (mendekati 0) maka akan diperoleh solusi yang lebih optimal. Disamping itu juga bergantung pada penentuan bilangan fuzzy triangular "di sekitar $m$ " atau "kira-kira $m$ ", yaitu jika $m_{1}(m-a=c-m)$ semakin kecil maka diperoleh solusi yang lebih optimal. 


\section{DAFTAR PUSTAKA}

Ali, M.F., 2001. A differential equation approach to fuzzy vector optimization problems and sentivity analysis. Fuzzy Sets and Systems. 119(1). pp 87-95.

Ammar, E.I., 1997. Stability of multiobjective NLP problems with fuzzy parameters in the objective and constraints functions. Fuzzy Sets and Systems. 109. pp 225-234.

Sakawa, M., 1993. Fuzzy Sets and Interactive Multiobjective Optimization. Plenum Press. New York. 